\title{
Article
}

\section{Biochemical alterations in duckweed and algae induced by carrier solvents: Selection of an appropriate solvent in toxicity testing}

Hu, Li-Xin, Tian, Fei, Martin, Francis L and Ying, Guang-Gou

Available at http://clok.uclan.ac.uk/17392/

Hu, Li-Xin, Tian, Fei, Martin, Francis L ORCID: 0000-0001-8562-4944 and Ying, Guang-Gou (2017) Biochemical alterations in duckweed and algae induced by carrier solvents: Selection of an appropriate solvent in toxicity testing.

Environmental Toxicology and Chemistry . ISSN 0730-7268

It is advisable to refer to the publisher's version if you intend to cite from the work. http://dx.doi.org/10.1002/etc.3804

For more information about UCLan's research in this area go to

http://www.uclan.ac.uk/researchgroups/ and search for <name of research Group>.

For information about Research generally at UCLan please go to http://www.uclan.ac.uk/research/

All outputs in CLoK are protected by Intellectual Property Rights law, including Copyright law. Copyright, IPR and Moral Rights for the works on this site are retained by the individual authors and/or other copyright owners. Terms and conditions for use of this material are defined in the policies page. 


\section{Environmental Toxicology and Chemistry}

Environmental Toxicology

BIOCHEMICAL ALTERATIONS IN DUCKWEED AND ALGAE INDUCED BY CARRIER

SOLVENTS: SELECTION OF AN APPROPRIATE SOLVENT IN TOXICITY TESTING

Li-Xin Hu, Fei Tian, Francis L. Martin, and Guang-Guo Ying

Environ Toxicol Chem., Accepted Article • DOI: 10.1002/etc.3804

\section{Accepted Article}

"Accepted Articles" are peer-reviewed, accepted manuscripts that have not been edited, formatted, or in any way altered by the authors since acceptance. They are citable by the Digital Object Identifier (DOI). After the manuscript is edited and formatted, it will be removed from the "Accepted Articles" Web site and published as an Early View article. Note that editing may introduce changes to the manuscript text and/or graphics which could affect content, and all legal disclaimers and ethical guidelines that apply to the journal pertain. SETAC cannot be held responsible for errors or consequences arising from the use of information contained in these manuscripts.

This article is protected by copyright. All rights reserved 
BIOCHEMICAL ALTERATIONS IN DUCKWEED AND ALGAE INDUCED BY CARRIER

SOLVENTS: SELECTION OF AN APPROPRIATE SOLVENT IN TOXICITY TESTING

Running title: Selection of carrier solvents in toxicity testing

$$
\text { Li-Xin Hu, }{ }^{\mathrm{a}, \mathrm{b}} \text { Fei Tian, }{ }^{\mathrm{a}} \text { Francis L. MARtin, }{ }^{\mathrm{c}} \text { (iD } \text { and GuAnG-GuO Ying }{ }^{\mathrm{a}, \mathrm{d}, * \text { (iD }}
$$

${ }^{a}$ State Key Laboratory of Organic Geochemistry, Guangzhou Institute of Geochemistry, Chinese Academy of Sciences, Guangzhou, China

\author{
${ }^{\mathrm{b}}$ University of Chinese Academy of Sciences, Beijing, China
}

${ }^{\mathrm{c}}$ School of Pharmacy and Biomedical Sciences, University of Central Lancashire, Preston, UK

${ }^{\mathrm{d}}$ The Environmental Research Institute, MOE Key Laboratory of Environmental Theoretical Chemistry, South China Normal University, Guangzhou, China

* Address correspondence to guang-guo.ying@gig.ac.cn

This article contains online-only Supplemental Data

This article is protected by copyright. All rights reserved

Submitted 8 December 2016; Returned for Revision 5 March 2017; Accepted 22 March 2017

This article is protected by copyright. All rights reserved 
Abstract: Carrier solvents are often used in aquatic toxicity testing for test chemicals with hydrophobic properties. However, the knowledge of solvent effects on test organisms remains limited. This study aimed to understand biochemical effects of the four common solvents ((methanol, ethanol, acetone and dimethylsulfoxide (DMSO)) on two test species Lemna minor and Raphidocelis subcapitata by applying Fourier transform infrared spectroscopy (FTIR) coupled with multivariate analysis in order to select appropriate solvents in the toxicity testing. The results showed biochemical variations associated with solvent treatments at different doses on test species. From the obtained infrared spectra, the structures of lipid membrane and protein phosphorylation in the test species were found sensitive to the solvents. Methanol and ethanol mainly affected the protein secondary structure, while acetone and DMSO primarily induced the alterations of carbohydrate and proteins in the test species. The FTIR results demonstrated that methanol and ethanol showed higher biochemical alterations in the test species than acetone and DMSO, especially at the high doses $(0.1 \%$ and $1 \% \mathrm{v} / \mathrm{v})$. Based on the growth inhibition and FTIR spectroscopy, acetone and DMSO can be used as carrier solvent in the toxicity testing when their doses are lower than $0.1 \% \mathrm{v} / \mathrm{v}$. This article is protected by copyright. All rights reserved

Keywords: Toxicity test; Carrier solvent; FTIR spectroscopy; Biochemical fingerprint 


\section{INTRODUCTION}

Considering the insoluble or sparingly soluble property of some chemicals, it becomes crucial to use a carrier solvent in toxicity testing. Methanol, ethanol, acetone and dimethylsulfoxide (DMSO) are the most commonly used solvents in toxicity tests [1]. However, their potential effects on test organisms have become a crucial issue. OECD has recommended a maximum acceptable solvent concentration of $0.01 \% \mathrm{v} / \mathrm{v}$, and the United States environmental protection agency (US EPA) has set $0.05 \%$ solvent as the maximum concentration for acute toxicity tests $[1,2]$. The solvent doses in the aquatic assays are often higher than these limits of recommendation because of the low solubility of test chemicals, small test volume and other limitations [3]. Although the carrier solvents are often used for the toxicity testing of hydrophobic chemicals, the toxic effects and toxicity data of these solvents are still very limited, especially for those subtle changes at molecular level. Thus there is a need for running concurrent solvent and negative controls to assess carrier influence in these assays.

There have been some reports on toxicity of some carrier solvents to alga, fish, invertebrate and other organisms [4-7]. Syed et al. [8] studied the effect of acetone, acetonitrile, dimethyl sulfoxide (DMSO), ethanol and methanol on oxidative phosphorylation (ATP synthesis) in rat liver mitochondria, and found that all the organic solvents inhibited the oxidative phosphorylation in a concentration dependent manner, but with differences in potencies. Among the tested organic solvents, acetonitrile and acetone were more potent than ethanol, methanol, and DMSO [8]. Ma et al. [5] assessed the toxicity of seven solvents (acetone, ethanol, methanol, DMSO, $N, N$-dimethyl-formamide, furanidine and acetidin) to green alga, and indicate that acetone and DMSO would be suitable solvents to use in toxicity bioassays involving algae. As a higher plant, Lemna gibba was found to be much more This article is protected by copyright. All rights reserved 
sensitive to methanol when compared with some algae, and the inhibitory effect was strongly associated with the increase in the nonphotochemical energy dissipation [9]. Chen et al. [10] investigated the behavior effects of ethanol and DMSO to zebrafish embryo-larvae, and observed that the solvents at low concentrations could alter locomotor activity of larval zebrafish without causing any observable developmental defects. Therefore, solvent effects in toxicity bioassays should be further investigated, especially at the biochemical level.

Duckweed (Lemna minor) and alga (Raphidocelis subcapitata) are common test species in aquatic toxicity tests of chemicals [11]. Their effects can be further explored at the subcellular level using Fourier transform infrared spectroscopy (FTIR). FTIR is a useful tool to provide detailed biochemical information according to the vibration of the chemical bonds [12], and it can be used as endpoints in toxicity testing [13]. For instance, the vibration in $3000-2800 \mathrm{~cm}^{-1}$ are often assigned to the stretching vibration of $\mathrm{C}-\mathrm{H}$ of $\mathrm{CH}_{3}$ and $\mathrm{CH}_{2}$, and the vibrations of $1750-1700 \mathrm{~cm}^{-1}$ are associated with $\mathrm{C}=\mathrm{O}$ stretching vibration of lipid, vibrations in these regions can indicate the structure and degree of oxidation of the lipid [13]. $1700-1580 \mathrm{~cm}^{-1}$ mainly represents the $\mathrm{C}=\mathrm{O}$ stretching vibrations coupled with C-N stretching vibrations of amide I, this region can indicate the secondary structure of protein [14]. The amide II is associated with the vibration of C-N stretching vibrations along with N-H in-plane bending vibration at $1580-1480 \mathrm{~cm}^{-1}$ region [15]. The biochemical alterations at 1250 and $1080 \mathrm{~cm}^{-1}$ are often related with asymmetric and symmetric phosphate stretching vibrations, the alterations at these bands may be an indicator of the nucleic acids changes [16]. The vibrations in $1200-900 \mathrm{~cm}^{-1}$ are often assigned to carbohydrate [17]. In order to extract the biomarkers to evaluate the biochemical effects induced by the reagents, a sophisticated unsupervised approach like principle component analysis and a powerful classification tool like linear discriminant analysis are applied to analyze the This article is protected by copyright. All rights reserved 
complicated IR data [18].

The aims of this study was to assess the alterations of biochemical information induced by four common carrier solvents (methanol, ethanol, acetone and DMSO), and to select an appropriate solvent and concentration in duckweed and alga toxicity testing for hydrophobic chemicals.

\section{MATERIALS AND METHODS}

\section{Reagents}

The solvents tested in this study included ethanol (99.9\%), methanol (99.99\%), acetone (99.9\%), dimethylsulfoxide (DMSO, 99.99\%). Ethanol and acetone were purchased from FUYU Chemical Co. (China), while methanol and DMSO were purchased from Merk Corporation (Germany). All solvent doses in the toxicity tests were given as percent (\%) volume/volume.

\section{Test species}

The duckweed Lemma minor used in this study was cultured in laboratory in the Swedish standard (SIS) medium (Table S1) under the following conditions: 2000 lx; 25 $\pm 1{ }^{\circ} \mathrm{C}$; Humidity, 60\%; day: night 14 h: 10 h. The alga Raphidocelis subcapitata was cultured in the Blue-Green (BG11) medium (Table S1) under the following conditions: $2000 \mathrm{~lx} ; 25 \pm 1{ }^{\circ} \mathrm{C}$; Humidity, $60 \%$; day: night $14 \mathrm{~h}$ : $10 \mathrm{~h}$.

\section{Toxicity testing}

Duckweed toxicity test. Exposure tests for duckweeds were conducted in a number of six well plates. Each well contained $10 \mathrm{~mL}$ of the SIS medium and 4 three-frond colonies of approximately the same size. Four doses $(1 \%, 0.1 \%, 0.01 \%$, and $0.001 \% \mathrm{v} / \mathrm{v})$ for each carrier solvent were used, and each treatment was replicated three times. All fronds were placed under the same conditions shown as above.

The number of fronds in each well was counted every two days and then the solution was renewed. At the end of the exposure, two fronds from each treatment were picked out for FTIR and biomass This article is protected by copyright. All rights reserved 
analysis. The fronds for FTIR analysis were fixed with $10 \%$ formalin in phosphate buffer saline (PBS) for $12 \mathrm{~h}[13]$.

Alga toxicity test. Exposure tests for algae were conducted in a series of 24 well plates. Each well contained $2 \mathrm{~mL}$ of BG11 medium and $1.0 \times 10^{4}$ cells $/ \mathrm{mL}$ of algae. Four doses $(1 \%, 0.1 \%, 0.01 \%$, and $0.001 \% \mathrm{v} / \mathrm{v}$ ) for each carrier solvent were used, and each treatment was replicated four times. The algal biomass in each well was measured at the absorbance of $437 \mathrm{~nm}$ each day using a microplate reader (BMG Labtech FLUOstar Omega) [19]. At the end of the exposure, the algal cells were centrifuged at $1000 \mathrm{~g}$ for $5 \mathrm{~min}$, washed with PBS and then fixed with 10\% formalin in PBS for $12 \mathrm{~h}$.

\section{FTIR spectroscopy and pre-processing of spectra data}

Duckweed fronds in $10 \%$ formalin in PBS were washed three times with milli-Q water, applied to $\mathrm{BaF}_{2}$ slides $(30 \times 3 \mathrm{~mm}, \mathrm{BTD}$, Tianjin), and then dried in the desiccator for $24 \mathrm{~h}$. For algal cells, the fixed cells were centrifuged at $1000 \mathrm{~g}$ for $5 \mathrm{~min}$, washed three times with milli-Q water and suspended with $100 \mu \mathrm{L}$ water, and $10 \mu \mathrm{L}$ of the mixture was dropped onto $\mathrm{a} \mathrm{BaF}_{2}$ slide for infrared measurement. IR spectra were obtained using a Bruker vertex 70 FTIR spectrometer (Bruker Optics Ltd., Germany) equipped with a Hyperion 1000 microscope, which contained a liquid nitrogen cooled detector. Instrument parameters were set at $64 \mathrm{scans}$, and $8 \mathrm{~cm}^{-1}$ resolution. Prior to starting each new slide, a background was taken. For each replication, approximately 50 IR spectra were acquired at different positions across each sample.

Raw data obtained from tested fronds were analyzed in the irootlab toolbox (http://irootlab.googlecode.com/) running on Matlab r2010a [20]. Each spectrum was cut at the C-H stretching vibration region $\left(3000-2800 \mathrm{~cm}^{-1}\right)$ and the biochemical fingerprint region $\left(1800-900 \mathrm{~cm}^{-1}\right)$ for further analysis. These two regions were then baseline corrected and normalized to the maximum This article is protected by copyright. All rights reserved 
peak, $1650 \mathrm{~cm}^{-1}$ for the biochemical region and $2920 \mathrm{~cm}^{-1}$ for the $\mathrm{C}-\mathrm{H}$ stretching region [13]. Following these preprocessing, a multivariate analysis, principal component analysis (PCA) and linear discriminant analysis (PCA-LDA) was applied to identify biochemical alterations [21]. As a powerful dimensionality reduction tools, PCA is applied to reduce numbers of wavenumbers to 10 PCs [22]. LDA was applied to discriminate groups with different treatments, and it could also minimize the within-class variances and maximize the inter-class variances [21]. In this study, the first LDA factor $\left(\mathrm{LD}_{1}\right)$ was used to represent the primary biochemical alterations induced by reagents, which was shown in scores plots. Cluster vectors were also used to describe the difference between treatment groups (color line) and the control (black straight line) [23].

\section{Statistical significance test}

To determine whether treatment groups were significantly different from the reference control, one-way analysis of variance (ANOVA) with Dunnett's post hoc tests was applied. A p value below 0.05 is regarded to be statistically significant. All ANOVA analyses were performed in GraphPad Prism 5 (GraphPad Software, USA).

\section{RESULTS}

\section{Growth inhibition effects}

The growth inhibitions of duckweed fronds and algal cells under different test concentrations of the solvents are shown in Figure 1. For duckweeds, with the increasing concentrations of the tested solvents, the growth inhibition rates were gradually increasing. Compared with the reference control, the four solvents at the low doses $(0.001 \%$ and $0.01 \% \mathrm{v} / \mathrm{v})$ had little difference in growth inhibition. While their concentrations increased up to $0.1 \%$, the fronds treated with methanol and ethanol were significantly inhibited, with the inhibition rate exceeding $50 \%$, while the fronds treated with acetone This article is protected by copyright. All rights reserved 
and DMSO shown little effect on inhibition. When the fronds were exposed to the reagents at $1 \% \mathrm{v} / \mathrm{v}$, they all showed different degrees of inhibition. In addition to the growth inhibition effect, some morphological differences of fronds were noticed, and the differences included the area, transparency and color of the fronds. Compared with the low doses $(0.001 \%$ and $0.01 \% \mathrm{v} / \mathrm{v})$, the fronds treated with the high doses $(0.1 \%$ and $1 \% \mathrm{v} / \mathrm{v})$ showed smaller, more transparent and pale features. Besides, the fronds exposed to methanol and ethanol at the high doses $(0.1 \%$ and $1 \% \mathrm{v} / \mathrm{v})$ emerged with leaking cytosol.

For algae, the dose related effects were not evident, except for the ethanol group. The growth inhibition for the methanol group showed little variations with the inhibition rate remaining at about $10 \%$ with the increasing doses. The acetone group and DMSO group showed little change in growth inhibition at the low doses, and a slight stimulatory effect at the high doses.

\section{Biochemical Effects}

Duckweeds. To visualize the biochemical effects in duckweeds, integrated FTIR data obtained from the exposure experiment were analyzed with multivariate analysis. Throughout the spectral region, C-H stretching vibration region (3000 to $2800 \mathrm{~cm}^{-1}$ ) and biochemical fingerprint region (1800 to 900 $\mathrm{cm}^{-1}$ ), there were no clear differences between different treatment groups. Considering the large amounts of spectra obtained and its multidimensional character, PCA - LDA was applied to discriminate different categories and identify biomarkers associated with biochemical alterations. Scores plots in two-dimensions (Figure 2) showed differences between different classes, nearness in spectral points of classes implies similarity, while segregation of classes indicates dissimilar. Clusters vectors indicated the distinguishing features induced by the treatments compared to the reference control. The effects associated with different treatments were achieved by calculating the distance This article is protected by copyright. All rights reserved 
along $\mathrm{LD}_{1}$ from the mean spectra of treatment classes and the reference control.

Compared with the control, the methanol group induced distinct, statistically significant $(\mathrm{p}<0.001)$ dose related alterations at the high doses $(0.1 \%$ and $1 \% \mathrm{v} / \mathrm{v})$ in biochemical fingerprint (Figure $2 \mathrm{a})$. Following exposure of fronds to the low doses $(0.001 \%$ and $0.01 \% \mathrm{v} / \mathrm{v})$ of the solvent, a slight separation from the reference control along $\mathrm{LD}_{2}$ but not $\mathrm{LD}_{1}$ was observed. This phenomenon shows that the low dose treatments induced small alterations when compared to the significant biochemical effects caused by the high dose treatments. For the high dose treatments, there was a clear separation along $\mathrm{LD}_{1}$ in $\mathrm{C}-\mathrm{H}$ stretching vibration region (Figure $3 \mathrm{a}$ ).

In clusters vectors, we can identify wavenumbers distinguishing the control from the methanol treatments. The main alterations induced with the high methanol doses $(1 \%$ and $0.1 \% \mathrm{v} / \mathrm{v})$ included vibrations in absorbance spectra associated with lignin $\left(\sim 1600 \mathrm{~cm}^{-1}\right)$, lipids $\left(\sim 1740 \mathrm{~cm}^{-1}\right)$, Amide II $\left(1550 \mathrm{~cm}^{-1}\right)$, carbohydrate $\left(\sim 1150 \mathrm{~cm}^{-1}\right)$ and protein phosphorylation $\left(980 \mathrm{~cm}^{-1}\right)$. Only slight biochemical alterations were induced by the low doses $(0.01 \%$ and $0.001 \% \mathrm{v} / \mathrm{v})$ when compared with the control. The main alterations associated with $0.01 \% \mathrm{v} / \mathrm{v}$ methanol treatment included vibrations in absorbance spectra associated with lipids $\left(\sim 1700 \mathrm{~cm}^{-1}\right)$, protein (amino acid residue $\left(1420 \mathrm{~cm}^{-1}\right)$ ), carbohydrate $\left(\sim 1100 \mathrm{~cm}^{-1}\right)$ and starch $\left(1000 \mathrm{~cm}^{-1}\right)$. The main alterations associated with $0.001 \% \mathrm{v} / \mathrm{v}$ methanol treatment included vibrations in absorbance spectra associated with starch $\left(\sim 1025 \mathrm{~cm}^{-1}\right)$ and protein phosphorylation $\left(980 \mathrm{~cm}^{-1}\right)$ (Figure $\left.2 \mathrm{~b}\right)$.

The dose-related alterations in $\mathrm{C}-\mathrm{H}$ stretching region by methanol treatments were observed in $\mathrm{LD}_{1}$ (Figure $\left.3 \mathrm{a}\right)$. There was no overlap of spectral points in $1 \% \mathrm{v} / \mathrm{v}$ methanol treatment, compared to the other doses. Clusters vectors in $\mathrm{C}-\mathrm{H}$ region showed that the main difference in $\mathrm{LD}_{1}$ was caused by C-H stretching vibration of $\mathrm{CH}_{3}\left(\sim 2960 \mathrm{~cm}^{-1}\right)$ and $\mathrm{CH}_{2}\left(\sim 2920 \mathrm{~cm}^{-1}\right)$, and this spectral alteration was This article is protected by copyright. All rights reserved 
assigned to lipid (Figure 3b).

Exposure of fronds to ethanol also resulted in a dose-related response in biochemical information (Figure 2c). Compared with the reference control, there are two distinct dose related alterations in 2-D scores plots showed distinct dose-related patterns. The overlapping at the high doses indicated similarity in biochemical alterations; and a small separation of the low doses from the control along $\mathrm{LD}_{2}$ indicated slight biochemical alterations at the low doses. As shown in CV plots, the main alterations at the high ethanol doses included amide I $\left(1627 \mathrm{~cm}^{-1}\right)$, lipid $\left(1740 \mathrm{~cm}^{-1}\right)$, and amide II $\left(1542 \mathrm{~cm}^{-1}\right)$ (Figure $\left.2 \mathrm{~d}\right)$. Subtle alterations at the low doses included carbohydrate $\left(1164 \mathrm{~cm}^{-1}\right)$, amide I $\left(1608 \mathrm{~cm}^{-1}\right)$ and lipid $\left(1735 \mathrm{~cm}^{-1}\right)$.

Complete separation of the high ethanol doses from the low does and control was observed in $\mathrm{C}-\mathrm{H}$ region (Figure 3c). The alterations associated with ethanol exposure included symmetric and asymmetric $\mathrm{C}-\mathrm{H}$ stretching vibrations of $\mathrm{CH}_{3}$ and $\mathrm{CH}_{2}$ (Figure $3 \mathrm{~d}$ ).

For acetone treatments, there were incomplete segregations between each treatment and the control in both biochemical fingerprint region and C-H region (Figure 2e). But not much overlap in spectral points was observed between the high doses and low doses, so their spectral points were divided at $\mathrm{LD}_{1}$ in biochemical region. The alterations induced by the high acetone doses were mainly found on starch $\left(\sim 1050 \mathrm{~cm}^{-1}\right)$, nucleic acids $\left(1064 \mathrm{~cm}^{-1}\right)$ and protein $\left(1625 \mathrm{~cm}^{-1}\right)$, while for the low acetone doses only subtle changes were found on protein (amide I and amide II), carbohydrate (1164 $\left.\mathrm{cm}^{-1}\right)$ and nucleic acids $\left(1083 \mathrm{~cm}^{-1}\right)$ (Figure $\left.2 \mathrm{f}\right)$. Little separation was observed along $\mathrm{LD}_{2}$ in $\mathrm{C}-\mathrm{H}$ stretching vibrations (Figure 3e), and the $\mathrm{CV}$ plots showed dose-related biochemical variations on $\mathrm{CH}_{2}$ $\left(2850 \mathrm{~cm}^{-1}\right)$ (Figure 3f).

For DMSO treatments, incomplete segregations were observed between each treatment and the This article is protected by copyright. All rights reserved 
control (Figure 2g). No overlap was found between the $1 \% \mathrm{v} / \mathrm{v}$ dose and the other doses in biochemical region and C-H stretching region. Spectral alterations induced by DMSO treatments were mainly associated with amide I $\left(\sim 1600 \mathrm{~cm}^{-1}\right)$, amide II $\left(\sim 1520 \mathrm{~cm}^{-1}\right)$ and starch $\left(\sim 1000 \mathrm{~cm}^{-1}\right)$ (Figure $\left.2 \mathrm{~h}\right)$. The main alterations for the $0.001 \% \mathrm{v} / \mathrm{v}$ DMSO treatment included vibrations associated with amide I (1608 $\left.\mathrm{cm}^{-1}\right)$, amide II $\left(\sim 1520 \mathrm{~cm}^{-1}\right)$, while those for the $1 \% \mathrm{v} / \mathrm{v}$ DMSO treatment included vibrations associated with starch $\left(1030 \mathrm{~cm}^{-1}\right)$, and carbohydrate $\left(1126 \mathrm{~cm}^{-1}\right)$. In $\mathrm{C}-\mathrm{H}$ stretching vibrations region, the highest dose induced marked spectral alterations, with all kinds of $\mathrm{C}-\mathrm{H}$ stretching vibrations being changed (Figure $3 g$ and $3 h$ ).

Algae. The methanol treatments induced dose-related alterations in algal cells. The spectra of methanol treatments were partially overlapped with the control (Figure 4a and 5a), suggesting only slight alterations in algal cells induced by the methanol doses. In CV plots (Figure 4b), the distinguishing wavenumbers were mainly focused on amide I, carbohydrate and DNA/RNA at the high doses, and proteins and starch at the low doses.

For ethanol treatments, clear segregations were observed between the treatment groups and the control and the separation from the control increased with the doses along $\operatorname{LD}_{1}$ (Figure $4 \mathrm{c}$ and $5 \mathrm{c}$ ). The alterations obtained at $\mathrm{CH}$ stretching region were the same as the biochemical fingerprint region, with the principal alterations on protein (amide I and amide II) and lipid related vibrations (Figure 4d and $5 d)$.

For acetone treatments, no clear separation was found between the treatments and the control at both biochemical fingerprint region and $\mathrm{CH}$ stretching region (Figure $4 \mathrm{e}$ and $5 \mathrm{e}$ ). Spectra alterations induced by acetone were generally associated with starch, amide I and protein phosphorylation (Figure 4f).

This article is protected by copyright. All rights reserved 
For the DMSO treatments, the differences between different treatments and the control were very subtle, and the coefficient values were very small at the biochemical region (Figure $4 \mathrm{~g}$ and $4 \mathrm{~h}$ ). Spectra alterations at $\mathrm{CH}$ stretching region shown a dose related effects, and the ratio of vibration on $\mathrm{CH}_{2}$ and $\mathrm{CH}_{3}$ were also changed (Figure $5 \mathrm{~g}$ and $5 \mathrm{~h}$ ).

\section{DISCUSSION}

The results from the present study showed species specific dose-related effects from the carrier solvents based on the traditional endpoints and biochemical endpoints. For the two test species (Lemma minor and Raphidocelis subcapitata), acetone and DMSO clearly showed less growth effects and biochemical alterations than methanol and ethanol. The result from the present study is also consistent with a previous study [3], which indicated that the solvent toxicity was ethanol, methanol > acetone > DMSO. Compared with the reference control, the distances between the treatment groups and the reference control on duckweed (Figure 2) were greater than the distances on alga (Figure 4). As the clusters vectors plots shown, the height of the peaks of duckweed ranged from 0.1 to 0.2 , while the height of peaks of alga was limited to 0.015 . So the solvents had less toxic effects on algae than duckweeds, especially at the high doses.

This may be due to fast algal cell reproduction. The results based on the biomass and FTIR analysis showed consistency to some degree (Figure S1), but FTIR analysis gave us more information on specific biochemical alterations.

Since the cell is mainly constituted of lipid and protein, alterations of these two elements, especially the lipid, could disrupt the structure and function of cells [24]. The present study showed dose-related alterations of C-H stretching region due to the exposure to the solvents, which could lead to disorder of the $\mathrm{C}-\mathrm{H}$ chain in the phospholipid, and further affecting cell membrane permeability and This article is protected by copyright. All rights reserved 
fluidity $[25,26]$. Thus these solvents especially methanol and ethanol at the high doses could alter the structure of the membrane lipids, and induce the peroxidation of the membrane lipids. In accordance with the previous studies [27], our findings also provided the direct evidence to the relation between the biochemical mechanism of ethanol toxicity and the lipid peroxidation.

The change of protein structure would affect the normal function of organism and metabolic materials. The relative content of $\alpha$-helix, $\beta$-sheet and $\beta$-turn represents the stabilization of protein structure [28]. The vibrations associated with $1400 \mathrm{~cm}^{-1}$ are assigned to the amino acids residues, and the damage of these residues could affect the secondary structure [29]. Besides, the vibrations at 970 $\mathrm{cm}^{-1}$ are related to protein phosphorylation, which is associated with the structure of $\beta$-sheet [30]. The results from the present study showed alterations of $\beta$-sheet structure by the methanol, ethanol and acetone treatments, and changes of $\alpha$-helix by the methanol treatment. The alterations of amino acids residues were associated with the acetone and DMSO groups. Protein phosphorylation was observed for the treatments of all four solvents, suggesting sensitive response to the carrier solvents.

The alterations of DNA/RNA are always associated with the bands at $1250 \mathrm{~cm}^{-1}$ and $1080 \mathrm{~cm}^{-1}$, and these two bands are assigned to asymmetric and symmetric stretching vibration of phosphodiester linkage [31]. The alterations of phosphodiester linkage were detected in the present study for the four solvents, even at the doses below the OECD recommend limit. The alterations of carbohydrates are mainly reflected on the band of $1000 \mathrm{~cm}^{-1}$ to $1200 \mathrm{~cm}^{-1}$ [32]. These characteristic peaks are related to the photosynthesis of plant cells. According to the present study, acetone and DMSO at the high doses might result in the changes of carbohydrates.

Based on the biochemical alterations and PCA - LDA scores plots, appropriate solvents can be selected for use in duckweed and alga toxicity testing. For duckweed, a clear separation of the high This article is protected by copyright. All rights reserved 
doses $(1 \%$ and $0.1 \% \mathrm{v} / \mathrm{v})$ from the low doses $(0.01 \%$ and $0.001 \% \mathrm{v} / \mathrm{v})$ and the control was observed for methanol and ethanol treatments in biochemical region, suggesting significant effects of methanol and ethanol on algal cells (Figure 2). In contrast, overlapping for acetone and DMSO treatments was observed, indicating less biochemical effects from these two solvents. Much higher growth inhibition rates were found for both methanol and ethanol than acetone and DMSO at the high doses (Figure 1). This suggests that methanol and ethanol are not suitable to be used as carrier solvents at the high doses $(1 \%$ and $0.1 \% \mathrm{v} / \mathrm{v})$ in duckweed toxicity testing. Both the present study and previous study [9] showed sensitivity of duckweeds to methanol when compared with algae.

For algae, a clear segregation of different doses was only observed for ethanol, while overlapping for the other three solvents (Figure 4). Previous studies $[4,5]$ investigated toxicity of chemical solvents on algae based on growth inhibition. They found that methanol and ethanol are unsuitable for toxicity testing, while acetone and DMSO would be suitable solvents to use in toxicity bioassays involving algae.

\section{CONCLUSION}

The results from this study showed that biochemical alterations in the test organisms duckweeds and algae could be induced by the carrier solvents even at the low doses. The effects to the two test species varied among the four solvents, and slight differences were found between the two species. Methanol and ethanol generally caused more severe toxic effects than acetone and DMSO; thus acetone and DMSO are better carrier solvents for hydrophobic chemicals in duckweed and alga toxicity testing.

For other toxicity tests, a preliminary experiment is essential to find out what solvent and dose should be used before testing. It is also crucial to ensure that the solvent used in the testing has no toxic effects, whether in the growth and development, or in the subcellular biochemical information. The solvent This article is protected by copyright. All rights reserved 
control should be included together with the toxicity test, while the interaction between the test chemical and carrier solvent should also be avoided.

Supplemental Data - The Supplemental Data are available on the Wiley Online Library at DOI: 10.1002/etc.Xxxx.

Acknowledgment - The authors would like to acknowledge the financial support from Guangdong Provincial Applied Science and Technology Research Program (2015B020235012), National Natural Science Foundation of China (U1401235) and National Water Pollution Control Program of China (2014ZX07206-005). Thanks to J.Y. Li at Lancaster University for his assistance in bio-spectroscopy analysis.

Data Availability - Data is included in the supporting materials. 


\section{REFERENCES}

1. Chen TH, Wang YH, Wu YH. 2011. Developmental exposures to ethanol or dimethylsulfoxide at low concentrations alter locomotor activity in larval zebrafish: implications for behavioral toxicity bioassays. Aquat Toxicol 102:162-166.

2. Hutchinson T, Shillabeer N, Winter M, Pickford D. 2006. Acute and chronic effects of carrier solvents in aquatic organisms: a critical review. Aquat Toxicol 76:69-92.

3. Okumura Y, Koyama J, Takaku H, Satoh H. 2001. Influence of organic solvents on the growth of marine microalgae. Arch Environ Con Tox 41:123-128.

4. El Jay A. 1996. Toxic effects of organic solvents on the growth of Chlorella vulgaris and Selenastrum capricornutum. B Environ Contam Tox 57:191-198.

5. Ma J, Chen J. 2005. How to accurately assay the algal toxicity of pesticides with low water solubility. Environ Pollut 136:267-273.

6. David RM, Jones HS, Panter GH, Winter MJ, Hutchinson TH, Chipman JK. 2012. Interference with xenobiotic metabolic activity by the commonly used vehicle solvents dimethylsulfoxide and methanol in zebrafish (Danio rerio) larvae but not Daphnia magna. Chemosphere 88:912-917.

7. Stevens AS, Pirotte N, Plusquin M, Willems M, Neyens T, Artois T, Smeets K. 2015. Toxicity profiles and solvent-toxicant interference in the planarian Schmidtea mediterranea after dimethylsulfoxide (DMSO) exposure. J Appl Toxicol 35:319-326

8. Syed M, Skonberg C, Hansen SH. 2013. Effect of some organic solvents on oxidative phosphorylation in rat liver mitochondria: Choice of organic solvents. Toxicol in Vitro 27:2135-2141.

9. Dewez D, Dautremepuits C, Jeandet P, Vernet G, Popovic R. 2003. Effects of methanol on This article is protected by copyright. All rights reserved 
photosynthetic processes and growth of Lemna gibba. Photochem Photobi 78:420-424.

10. Chai J, Yan X, Liu RT, Wang M. 2011. Study on the toxic interaction of methanol, ethanol and propanol against the bovine hemoglobin $(\mathrm{BHb})$ on molecular level. Spectrochim Acta A 79:1406-1410. 11. Mkandawire M, Teixeira da Silva JA, Dudel EG. 2014. The Lemna bioassay: contemporary issues as the most standardized plant bioassay for aquatic ecotoxicology. Crit Rev Env Sci Tec 44:154-197.

12. Martin FL, Kelly JG, Llabjani V, Martin-Hirsch PL, Patel II, Trevisan J, Fullwood NJ, Walsh MJ. 2010. Distinguishing cell types or populations based on the computational analysis of their infrared spectra. Nat Protoc 5:1748-1760.

13. Hu LX, Ying GG, Chen XW, Huang GY, Liu YS, Jiang YX, Pan CG, Tian F, Martin FL. 2016. FTIR spectroscopy as a novel approach towards providing effect-based endpoints in duckweed toxicity testing. Environ Toxicol Chem 36(2):346-353

14. Baker MJ, Trevisan J, Bassan P, Bhargava R, Butler HJ, Dorling KM, Fielden PR, Fogarty SW, Fullwood NJ, Heys KA. 2014. Using Fourier transform IR spectroscopy to analyze biological materials. Nat Protoc 9:1771-1791.

15. Lewis PD, Lewis KE, Ghosal R, Bayliss S, Lloyd AJ, Wills J, Godfrey R, Kloer P, Mur LA. 2010. Evaluation of FTIR spectroscopy as a diagnostic tool for lung cancer using sputum. BMC Cancer 10:1. 16. Li J, Strong R, Trevisan J, Fogarty SW, Fullwood NJ, Jones KC, Martin FL. 2013. Dose-related alterations of carbon nanoparticles in mammalian cells detected using biospectroscopy: potential for real-world effects. Environ Sci Technol 47:10005-10011.

17. Li J, Ying GG, Jones KC, Martin FL. 2015. Real-world carbon nanoparticle exposures induce brain and gonadal alterations in zebrafish (Danio rerio) as determined by biospectroscopy techniques.

Analyst 140:2687-2695.

This article is protected by copyright. All rights reserved 
18. Llabjani V, Trevisan Jl, Jones KC, Shore RF, Martin FL. 2011. Derivation by infrared spectroscopy with multivariate analysis of bimodal contaminant-induced dose-response effects in MCF-7 cells.

Environ Sci Technol 45:6129-6135.

19. Gitchaiwat, A., Likhitlert, S., Kositchaiyong, A., Israngkura, K., Taptim, K., \& Sombatsompop, N. 2015. Uses of 2-hydroxypropyl-3-piperazinyl-quinoline carboxylic acid methacrylate and Terbutryn as algaecides in low-density polyethylene mulching films for agricultural applications. J Plast Film Sheet, 8756087915578467.

20. Trevisan J, Angelov PP, Scott AD, Carmichael PL, Martin FL. 2013. IRootLab: a free and open-source MATLAB toolbox for vibrational biospectroscopy data analysis. Bioinformatics:btt084.

21. Llabjani V, Trevisan J, Jones KC, Shore RF, Martin FL. 2010. Binary mixture effects by PBDE congeners $(47,153,183$, or 209) and PCB congeners (126 or 153) in MCF-7 cells: biochemical alterations assessed by IR spectroscopy and multivariate analysis. Environ Sci Technol 44:3992-3998. 22. Wagner H, Liu Z, Langner U, Stehfest K, Wilhelm C. 2010. The use of FTIR spectroscopy to assess quantitative changes in the biochemical composition of microalgae. J Biophotonics 3:557-566.

23. Li J, Tian M, Cui L, Dwyer J, Fullwood NJ, Shen H, Martin FL. 2016. Low-dose carbon-based nanoparticle-induced effects in A549 lung cells determined by biospectroscopy are associated with increases in genomic methylation. Sci Rep-UK 6.

24. Michael P, Salonen E, Terama E, Vattulainen I, Faller R, Lee BW, Holopainen J, Karttunen M. 2006. Under the influence of alcohol: the effect of ethanol and methanol on lipid bilayers. Biophys $\mathbf{J}$ 90:1121-1135.

25. Ozek NS, Tuna S, Erson-Bensan AE, Severcan F. 2010. Characterization of microRNA-125b expression in MCF7 breast cancer cells by ATR-FTIR spectroscopy. Analyst 135:3094-3102. This article is protected by copyright. All rights reserved 
26. Vileno B, Jeney S, Sienkiewicz A, Marcoux P, Miller L, Forró L. 2010. Evidence of lipid peroxidation and protein phosphorylation in cells upon oxidative stress photo-generated by fullerols. Biophys Chem 152:164-169.

27. Corongiu F P, Lai M, Milia A. 1983. Carbon tetrachloride, bromotrichloromethane and ethanol acute intoxication. New chemical evidence for lipid peroxidation in rat tissue microsomes. Biochemical Journal 212(3): 625-631.

28. Roccatano D, Colombo G, Fioroni M, Mark AE. 2002. Mechanism by which 2, 2, 2-trifluoroethanol/water mixtures stabilize secondary-structure formation in peptides: a molecular dynamics study. P Natl A Sci 99:12179-12184.

29. Rost B, Sander C. 1994. Combining evolutionary information and neural networks to predict protein secondary structure. Proteins 19:55-72.

30. Bah A, Vernon RM, Siddiqui Z, Krzeminski M, Muhandiram R, Zhao C, Sonenberg N, Kay LE, Forman-Kay JD. 2015. Folding of an intrinsically disordered protein by phosphorylation as a regulatory switch. Nature 519:106-109.

31. Obinaju BE, Fullwood NJ, Martin FL. 2015. Distinguishing nuclei-specific benzo [a] pyrene-induced effects from whole-cell alterations in MCF-7 cells using Fourier-transform infrared spectroscopy. Toxicology 335:27-34.

32. Butler HJ, McAinsh MR, Adams S, Martin FL. 2015. Application of vibrational spectroscopy techniques to non-destructively monitor plant health and development. Anal Methods-UK 7:4059-4070.

This article is protected by copyright. All rights reserved 
Figure 1. Dose-response curves showing the effects of different solvents on growth inhibition of duckweeds (A) and algae (B) at 96 hours. Standard deviations are represented by error bars.

Figure 2. Spectra of duckweeds in the region of biochemical fingerprint $\left(1800-900 \mathrm{~cm}^{-1}\right)$. Principle component analysis coupled with linear discriminant analysis (PCA-LDA) datasets was applied for the duckweeds exposed to different carrier solvents. PCA-LDA scores plots in two-dimensions (90\% confidence ellipsoids) were acquired from fronds of duckweed, the distance between different groups suggested the difference. Clusters vectors plots show the wavenumbers discriminating effects corresponding to the reference control. The heights of the clusters vectors peaks were proportional to the alterations of biochemical information compared to the reference control. The black horizontal line represents the control. The hint line represents a typical duckweed infrared spectrum of the biochemical fingerprint region (1800-900 cm-1). These scores plots are on the left. Panels represent: (a, b) methanol; (c, d) ethanol; (e, f) acetone; and (g, h) DMSO.

Figure 3. Spectra of duckweeds in the region of C-H stretching vibration region $\left(3000-2800 \mathrm{~cm}^{-1}\right)$. Principle component analysis coupled with linear discriminant analysis (PCA-LDA) datasets was obtained from the duckweeds exposed to different carrier solvents. PCA-LDA scores plots in two-dimensions (90\% confidence ellipsoids) were acquired from fronds of duckweed, the distance between different groups suggested the difference. Clusters vectors plots show the wavenumbers discriminating effects corresponding to the reference control. The black horizontal line represents the control. The hint line represents a typical duckweed infrared spectrum of C-H stretching vibration region (3000-2800 $\left.\mathrm{cm}^{-1}\right)$. These scores plots are on the left. Panels represent: (a, b) methanol; (c, d) ethanol; (e, f) acetone; and (g, h) DMSO. This article is protected by copyright. All rights reserved 
Figure 4. Spectra of algae in the region of biochemical fingerprint $\left(1800-900 \mathrm{~cm}^{-1}\right)$. Principle component analysis coupled with linear discriminant analysis (PCA-LDA) datasets was obtained from the duckweed exposed to different kinds of carrier solvents. PCA-LDA scores plots in two-dimensions (90\% confidence ellipsoids) were acquired from fronds of duckweeds; the distance between different groups suggested the difference. Clusters vectors plots show the wavenumbers discriminating effects corresponding to the reference control. The heights of the clusters vectors peaks were proportional to the alterations of biochemical information compared to the reference control. The black horizontal line represents the control. The hint line represents a typical algal infrared spectrum of the biochemical fingerprint region (1800-900 cm-1). These scores plots are on the left. Panels represent: (a, b) methanol; (c, d) ethanol; (e, f) acetone; and (g, h) DMSO.

Figure 5. Spectra of algae in the region of C-H stretching vibration region (3000-2800 $\left.\mathrm{cm}^{-1}\right)$. Principle component analysis coupled with linear discriminant analysis (PCA-LDA) datasets was obtained from the duckweeds exposed to different carrier solvents. PCA-LDA scores plots in two-dimensions (90\% confidence ellipsoids) were acquired from fronds of duckweeds; the distance between different groups suggested the difference. Clusters vectors plots show the wavenumbers discriminating effects corresponding to the reference control. The black horizontal line represents the control. The hint line represents a typical algae infrared spectrum of C-H stretching vibration region $\left(3000-2800 \mathrm{~cm}^{-1}\right)$. These scores plots are on the left. Panels represent: (a, b) methanol; (c, d) ethanol; (e, f) acetone; and (g, h)

\section{DMSO.}

This article is protected by copyright. All rights reserved 
Figure 1.
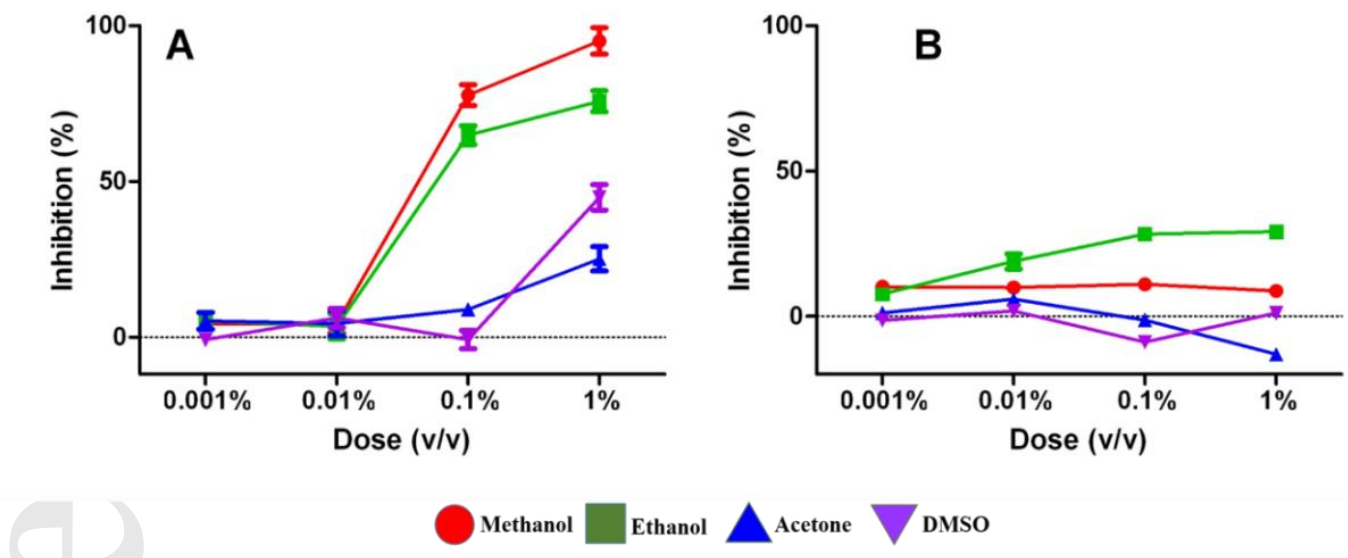

This article is protected by copyright. All rights reserved 
Figure 2.
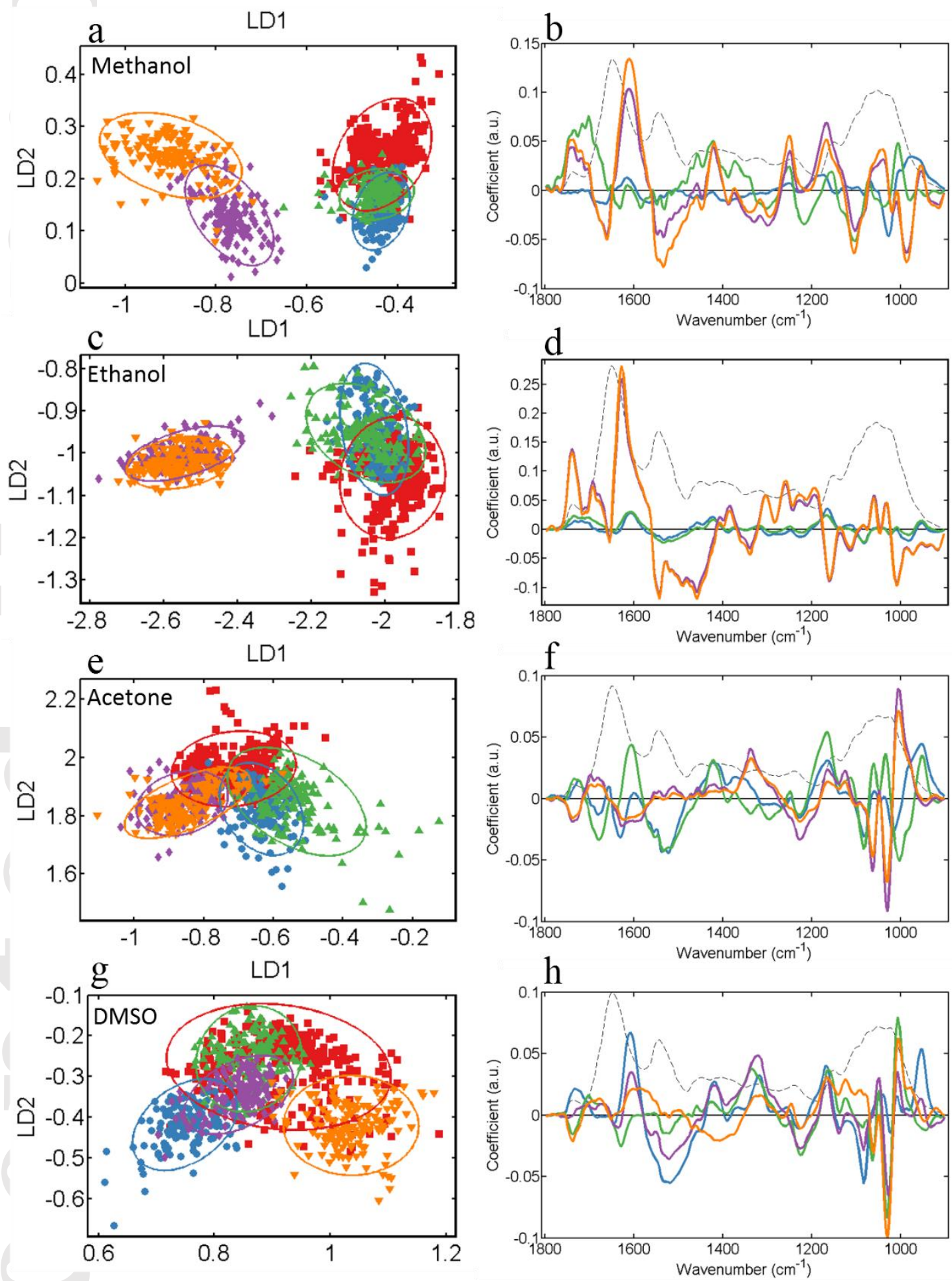

Control $\bigcirc 0.001 \% \triangle 0.01 \% \bigcirc 0.1 \% \bigcirc 1 \%$

This article is protected by copyright. All rights reserved 
Figure 3.
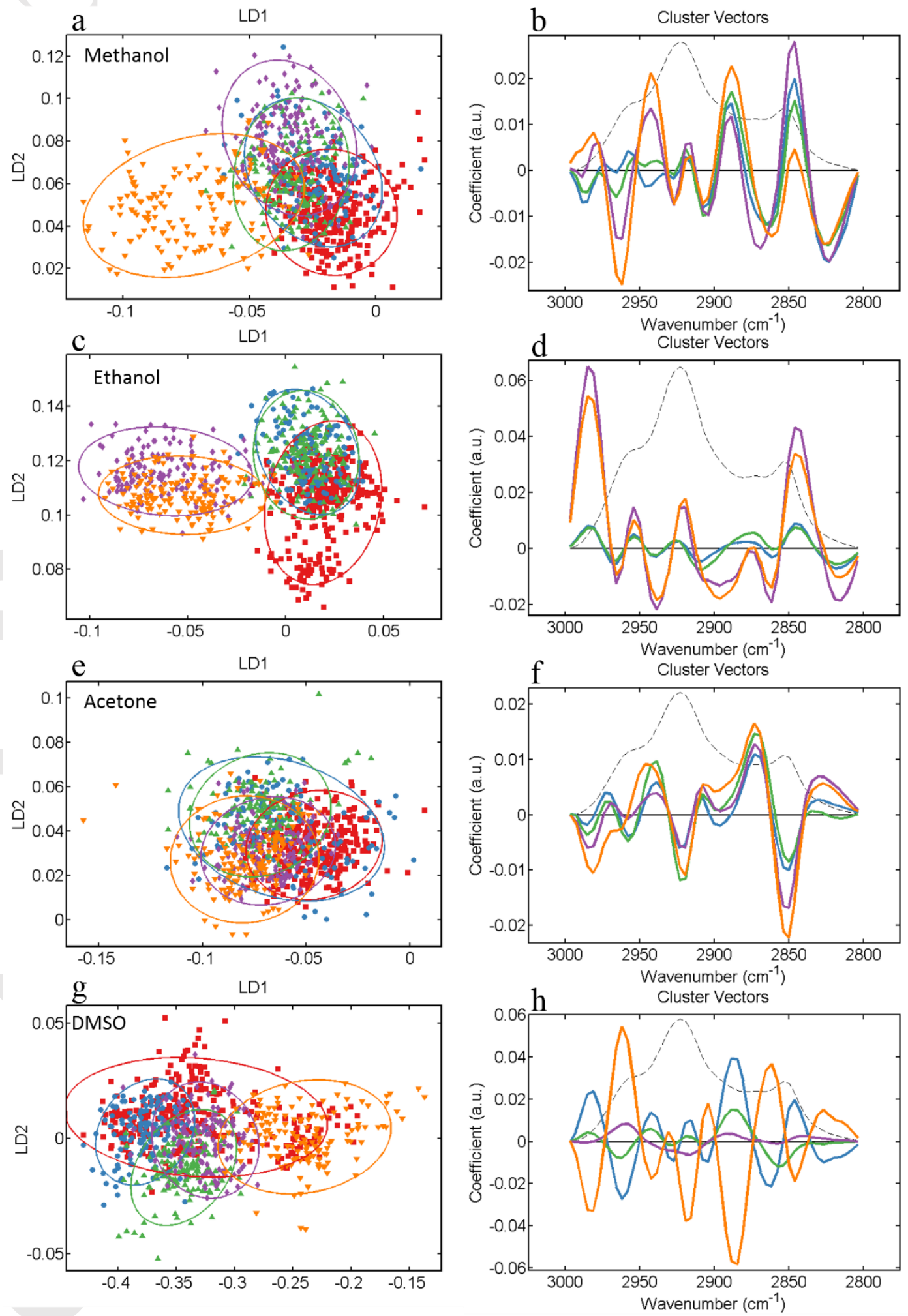

Control $0.001 \% \triangle 0.01 \% \longrightarrow 0.1 \% \backslash 1 \%$ 
Figure 4.
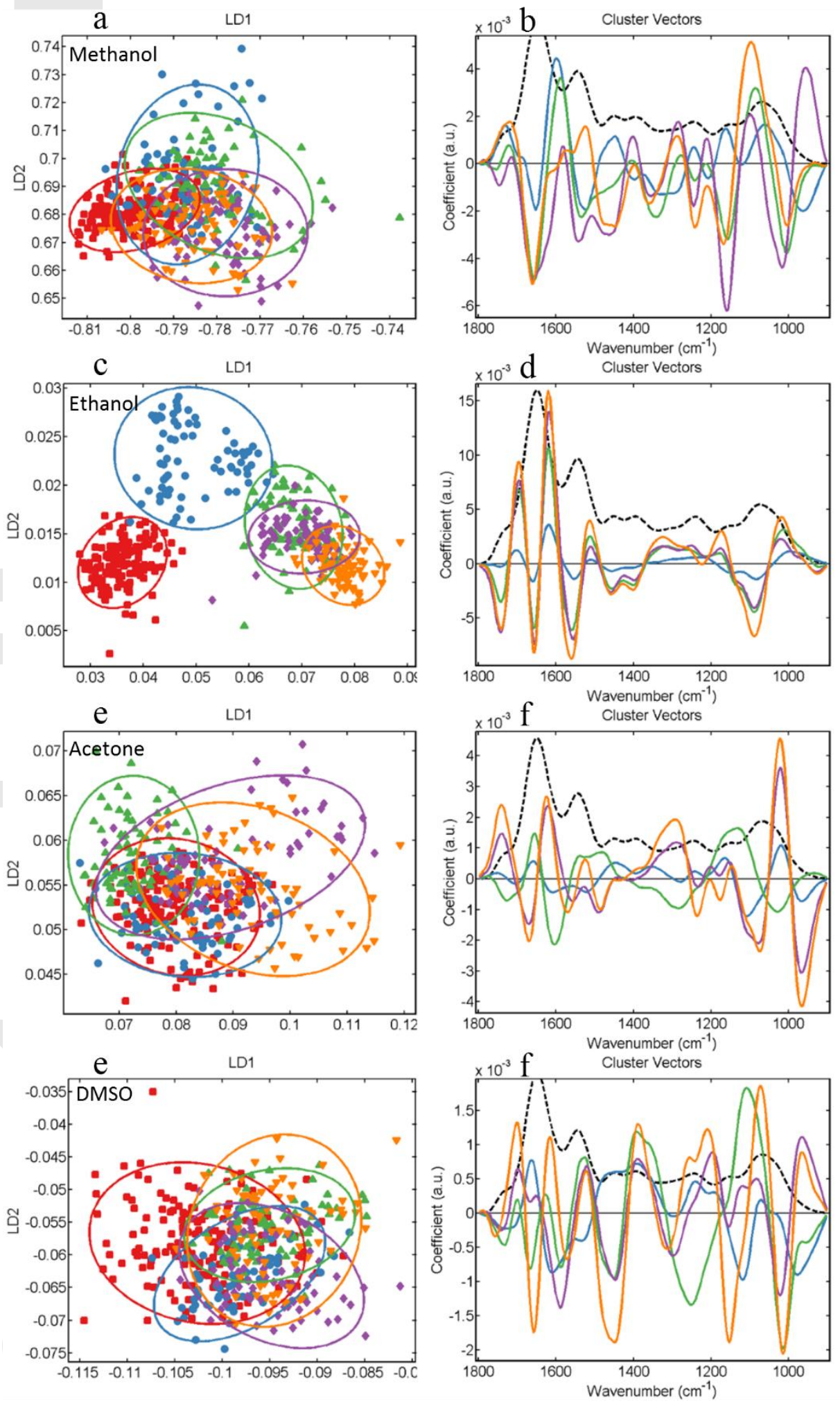

Control $\bigcirc 0.001 \% \triangle 0.01 \% \longrightarrow 0.1 \% \bigcirc 1 \%$ 
Figure 5.
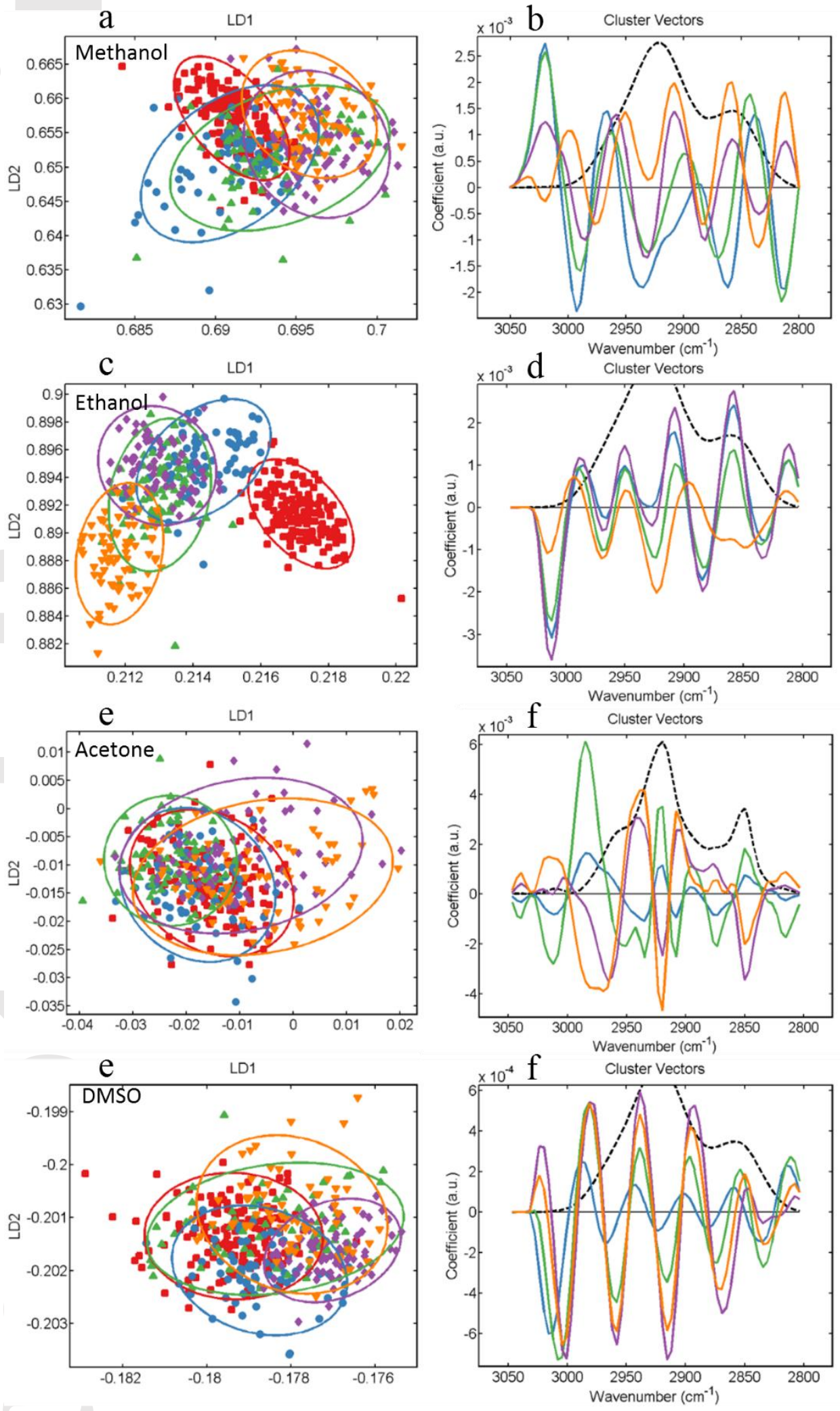

Control $0.001 \% \triangle 0.01 \% \bigcirc 0.1 \%{ }_{1 \%} \%$

This article is protected by copyright. All rights reserved 